Faculdade

de Ciências Econômicas UFRGS

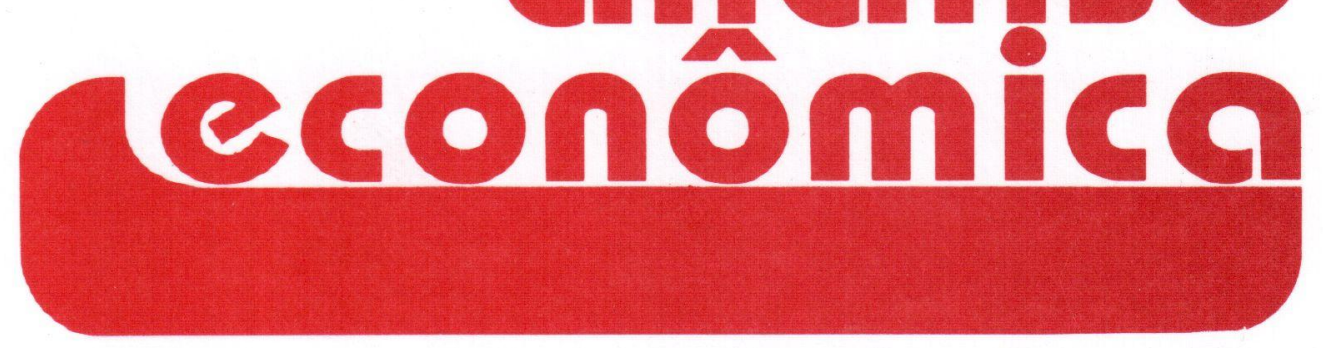

- A INTERNACIONALIzAÇÃo do Sistema FIINANCEIRO: 1990-1992

Lauro Lobo Burle

- GOVERNMENT INTERVENTION, INSTITUTIONAL FACTORS AND MARKET : AN ANALYSIS OF THE WAGE BARGAINING IN BRAZIL

Francisco Galrão Carneiro

- AINSTITUCIONALIZAÇÃO DA PREFERÊNCIA PELA LIQUIDEZ Albério Neves Filho

- PADRÕES MONETÁRIOS ALTERNATIVOS Fernando Carlos G. de Cerqueira Lima

- as contas nacionais e os custos AMBIENTAIS DA ATIVIDADE ECONÓMICA Charles C. Mueller

- LIVROS RECEBIDOS

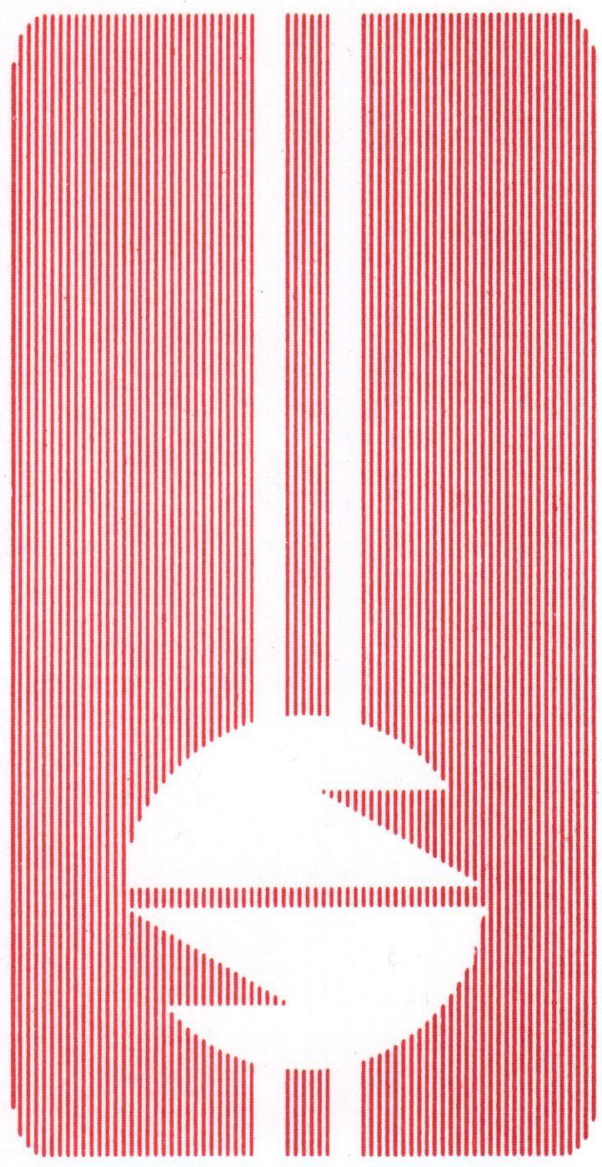


UNIVERSIDADE FEDERAL DO RIO GRANDE DO SUL Reitor Prof. Hélgio Henrique Casses Trindade

FACULDADE DE CIÊNCIAS ECONÔMICAS Diretor. Prof. Pedro Cézar Dutra Fonseca

CENTRO DE ESTUDOS E PEQUISAS ECONÔMICAS

Diretor. Prof. Paulo Alexandre Spohr

DEPARTAMENTO DE CIÉNCIAS ECONÔMICAS

Chefe: Prof. Achyles Barcelos da Costa

CURSO DE PÓS-GRADUAÇÃO EM ECONOMIA

Coordenador. Prof. Roberto Camps Moraes

CURSO DE PÓS-GRADUAÇĀO EM ECONOMIA RURAL

Coordenador. Prof. Atos Freitas Grawunder

CONSELHO EDITORIAL: Achyles Barcelos da Costa, Aray Miguel Feldens, Atos Freitas Grawunder, Carlos Augusto Crusius, Eugênio Lagemann, Fernando Ferrari Filho, Gentil Corazza, Juvir Luiz Mattuella, Marcelo Savino Portugal, Maria Imilda da Costa e Silva, Nali de Jesus de Souza, Nuno R. L. de Figueiredo Pinto, Otília Beatriz K. Carrion, Paulo Alexandre Spohr, Pedro Cezar Dutra Fonseca, Roberto Camps Moraes, Valter José Stülp, David Garlow (Wharton Econometrics Forecasts Association, E. U.A.), Edgar Augusto Lanzer (UFSC), Eleutério F. S Prado (USP), Fernando de Holanda Barbosa (FGV/RJ), Gustavo Franco (PUC/RJ), João Rogério Sanson (UFSC), Joaquim Pinto de Andrade (UnB), Juan H Moldau (USP), Werner Baer (Univ. de lllinois, E. U.A.).

COMISSÃO EDITORIAL: Atos Freitas Grawunder, Pedro Cezar Dutra Fonseca, Marcelo Savino Portugal, Roberto Camps Moraes.

EDITOR: Nali de Jesus de Souza

SECRETARIA: Cláudia Porto Silveira, Jeferson Luis Bittencourt e Vanete Ricachescki (revisão de textos).

FUNDADOR: Prof. Antônio Carlos Santos Rosa

Os materiais publicados na revista Análise Econômica são da exclusiva responsabilidade dos autores É permitida a reprodução total ou parcial dos trabalhos, desde que seja citada a fonte.

Aceita-se permuta com revistas congêneres. Aceitam-se, também, livros para divulgação, elaboração de resenhas e recensões.

Toda correspondência, material para publicaçăo (vide normas na terceira capa), assinaturas e permutas devem ser dirigidos ao seguinte destinatário:

PROF. NALI DE JESUS DE SOUZA

Revista Análise Econômica

Av. Joảo Pessoa, 52

CEP 90040-000 PORTO ALEGRE - RS, BRASIL.

Telefones: (051) 316-3348 e 316-3440

Fax: (051) 225-1067 


\section{A INTERNACIONALIZAÇÃO DO SISTEMA FINANCEIRO: 1990-1992*}

Lauro Lobo Burle"

\section{SINOPSE}

Este artigo analisa os fatores da internacionalização dos sistema financeiro nacional, enfatizando-se as mudanças institucionais da década de 60 , o endividamento externo das décadas de 70 e 80 , a reforma bancária de 1988 e a abertura da economia posterior a março de 1990. O texto procura mostrar o papel e o ajuste dos bancos estrangeiros em 1990/1992 e, por outro lado, a atuação dos bancos brasileiros no exterior nesse periodo. $O$ artigo conclui que os bancos estrangeiros contribuem para manter o perfil concentrado da renda interna e que a participação externa dos bancos nacionais é fundamental para a soberania interna.

\section{INTRODUÇÃO}

Este artigo objetiva analisar os fatos atuantes para a internacionalização do sistema financeiro nacional, entendendo-se como tal o aumento da participação das instituiçöes financeiras estrangeiras nos diferentes segmentos do mercado financeiro doméstico - ou seja, bancos comerciais, bancos de investimento, financeiras, empresas de leasing, distribuidoras, corretoras e seguradoras - em termos de depósitos, empréstimos, entre outras variáveis. Entende-se também por internacionalização financeira a expansão externa dos bancos brasileiros, ou mesmo simplesmente a elevação das operações cambiais no total das atividades dos bancos privados nacionais e estatais. Enfim, busca-se analisar as origens e os fatores que atuaram para que se acentuasse a internacionalização do sistema financeiro no Brasil, principalmente depois do final da década de 80 .

Além dessa introdução este artigo se subdivide em mais seis seções básicas. $\mathrm{Na}$ segunda seção, focaliza-se a internacionalização financeira resultante da reforma bancária-institucional da década de 60 , através da participação do investimento estrangeiro no setor financeiro no total investido no País, do percentual das instituiçōes financeiras estrangeiras nos depósitos captados e empréstimos outorgados e da participação das obrigações externas (ou passivo externo) no passivo bancário total. $\mathrm{Na}$ terceira seção, analisa-se a criação do banco múltiplo em 1988 e a abertura externa a partir de março de 1990, enfatizando-se os efeitos desses fatores para a maior internacionalização no sistema financeiro nesse periodo $\mathrm{Na}$ quarta seção, enfoca-se o desempenho operacional (liquidez,

\footnotetext{
* O autor agradece o apoio de Nali Jesus Souza e assume a responsabilidade pelas opiniões expressas

${ }^{* *}$ Professor da Faculdade de Economia, do Centro de Ensino Unificado de Brasília (CEUB).

Este artigo utiliza parte do trabalho de Baer (1986), onde o leitor interessado encontra, adicionalmente, uma análise sucinta da divida externa como eixo central da internacionalização financeira no Brasil.
}

\begin{tabular}{|c|l|}
\hline $\begin{array}{c}\text { Cód. AEA } \\
310\end{array}$ & $\begin{array}{l}\text { Palavras-chave: sistema financeiro nacional, abertura econômica, } \\
\text { ajuste dos bancos nacionais e estrangeiros }\end{array}$ \\
\hline
\end{tabular}

\begin{tabular}{|l|l|l|c|}
\hline ANÁLISE ECONÔMICA & ANO 12 & março/setembro 95 & p. 3-18 \\
\hline
\end{tabular}


capitalização, imobilização e rentabilidade) e o ajuste interno dos principais bancos estrangeiros operando no País, no período 1990/92. Na quinta seção, analisa-se a participação externa dos bancos nacionais estatais e privados, destacando-se a expansão das agências e escritórios no exterior e as principais atividades cambiais ao nivel interno, como as relacionadas com o comércio exterior e mercado de capitais. Finalmente, na última seção, são apresentadas as considerações finais.

\section{FATORES DA INTERNACIONALIZAÇÃO FINANCEIRA}

O Brasil é um país que embora sempre procurasse restringir a entrada de capital estrangeiro no sistema financeiro, apresentou uma crescente internacionalização nesse setor. Apesar da Lei 4131, de 1962, limitar em certos aspectos a instalação de bancos estrangeiros no pais, ${ }^{2}$ a verdade é que o sistema financeiro se internacionalizou de forma razoavelmente rápida com a vigência dessa lei, isto é, nas décadas de 60,70 e 80 . Para isso, atuaram destacadamente a reforma bancária de 1964 (Lei 4.595), ao promover a especialização financeira em bancos comerciais, bancos de investimento, financeiras e empresas de leasing; a Resolução 63 , que autorizou a captação externa de empréstimos em moeda estrangeira pelo sistema financeiro e; a instituição de minidesvalorizações cambiais em 1968, que propiciou a redução dos riscos das oscilações imprevistas da taxa de câmbio na captação externa (ver, Baer, 1986, p.13).

Na primeira metade dos anos 70 , o Governo estabeleceu o percentual máximo de $33 \%$ da participação estrangeira no capital dos bancos de investimento, das financeiras, das corretoras, das distribuidoras e, por fim, das empresas de leasing. Contudo essa decisão se mostrou inócua, visto que grande parte das instituições financeiras estrangeiras já tinham se instalado anteriormente. Além disso, existia o próprio interesse das instituições financeiras privadas nacionais em se associarem ao capital estrangeiro visando obter tecnologia e acesso a recursos externos. Por fim, destaca-se que, ao final da década de 80 , ocorreu processo semelhante de associações entre o capital nacional e o capital estrangeiro no sistema financeiro (inclusive bancos comerciais), mas na base de até $50 \%$ de participação externa, o que evidencia a maior liberalização do período atual.

Com relação aos bancos comerciais estrangeiros, constata-se, de acordo com Baer $(1986$, p. 146), que inúmeras instituições de grande porte atual encontram-se presentes no mercado brasileiro desde antes dos anos 60 , como os casos do Citibank, Banco Francês e Brasileiro (BFB), Sudameris e Banco de Tokyo. Na década de 60, alguns bancos americanos e europeus se instalaram no País, e nos anos 70 vários bancos latino-americanos e espanhóis o fizeram por meio de acordo de reciprocidade assinados com esses países (ver, Baer, 1986, p.26). Em 1984, o Banco NMB da Holanda se instalou no País, comprando o Banco Bafisud do Uruguai. Em 1988, o Banco Morgan americano se instalou no País, comprando a carta patente do $\mathrm{BCl}$ da Itália, que então saiu Além disso, existiram inúmeros outros bancos estrangeiros que se instalaram no Pais, ou bancos que foram criados com a participação do capital estrangeiro, depois da instituição do banco múltiplo, em 1988.

2 Na hipótese, por exemplo, do país-sede do banco estrangeiro impor restrições aos bancos brasileiros. 
Tabela 1 - Investimentos estrangeiros no setor financeiro - 1985/91 (US\$ milhões)

\begin{tabular}{|c|c|c|c|c|c|c|c|c|}
\hline \multirow{3}{*}{ Ano } & \multicolumn{6}{|c|}{ Setor financeiro } & \multirow{2}{*}{\multicolumn{2}{|c|}{$\begin{array}{c}\text { Total de } \\
\text { investimentos no Pais }\end{array}$}} \\
\hline & \multicolumn{2}{|c|}{ Investimento } & \multicolumn{2}{|c|}{ Reinvestimento } & \multicolumn{2}{|c|}{ Subtotal } & & \\
\hline & Valor (a) & $(\mathrm{a}) /(\mathrm{c}) \%$ & Valor (b) & $(b) /(c) \%$ & Valor (c) & $(a+b) \%$ & Valor (d) & (c)/(d) $\%$ \\
\hline 1985 & 696,7 & 65,5 & 3669 & 34,5 & 10634 & 100,0 & 25664,5 & 4,1 \\
\hline 1986 & 803,2 & 65,7 & 419,2 & 34,3 & $1.222,4$ & 100,0 & 27897,7 & 4,4 \\
\hline 1987 & 893,6 & 63,9 & 503,7 & 36,1 & $1.397,3$ & 100,0 & $31,458,0$ & 4,4 \\
\hline 1988 & 1200,0 & 70,4 & 504,1 & 29,6 & $1.704,1$ & 100,0 & 32030,9 & 5,3 \\
\hline 1989 & 1647,6 & 76,6 & 502,7 & 23,4 & 2. 150,3 & 100,0 & $34.286,5$ & 6,3 \\
\hline 1990 & $1,794,2$ & 76,4 & 555,0 & 23,6 & $2.349,2$ & 100,0 & 37143,4 & 6,3 \\
\hline 1991 & $2.405,3$ & 80,9 & 568,4 & 19,1 & $2.973,7$ & 100,0 & $38.580,2$ & 7,7 \\
\hline
\end{tabular}

Fonte: Boletim mensal do Banco Central do Brasil (1992)

Obs: : Bancos comerciais, bancos de investimento, seguradoras e outras instituições financeiras

Verifica-se pela Tab.1 que na segunda metade da década de 80 foi crescente a participação do investimento estrangeiro no setor financeiro no total investido no País. Ao mesmo tempo, constata-se que a proporção do reinvestimento no total do investimento estrangeiro no sistema financeiro caiu, sugerindo o aumento das remessas de lucros e dividendos do setor para o exterior. Além disso, de acordo com a Tab. 2, nota-se que os Estados Unidos, apesar de serem o principal investidor estrangeiro no sistema financeiro, vêm perdendo importância no investimento estrangeiro do sistema financeiro, e abrindo espaço para outros paises, como Japão, Reino Unido e Holanda (Tab 2). Ademais, a participação dos bancos comerciais e bancos múltiplos estrangeiros nos empréstimos e depósitos totais do sistema bancário privado se apresentou importante no biênio 1990/91. Em 1991, por exemplo, os bancos estrangeiros outorgaram $18,2 \%$ do total dos empréstimos dos bancos privados nacionais e estrangeiros (Tab 3 ).

Tabela 2 - Investimento estrangeiro no sistema financeiro por pais - 1989/1991 (US\$ milhões)

\begin{tabular}{l|r|r|r|r|r|r}
\hline \multirow{2}{*}{ Países } & \multicolumn{2}{|c|}{1989} & \multicolumn{2}{c|}{1990} & \multicolumn{2}{c}{1991} \\
\cline { 2 - 6 } & \multicolumn{1}{|c|}{ Valor } & Part. (\%) & \multicolumn{1}{|c|}{ Valor } & Part. (\%) & \multicolumn{1}{|c}{ Valor } & Part. (\%) \\
\hline Estados Unidos & 400,9 & 26,7 & 395,2 & 24,0 & 393,8 & 23,2 \\
Japão & 302,0 & 20,1 & 331,0 & 20,2 & 376,8 & 22,2 \\
França & 164,9 & 10,9 & 183,2 & 11,2 & 180,4 & 10,6 \\
Reino Unido & 144,0 & 9,6 & 180,4 & 10,9 & 170,6 & 10,2 \\
Alemanha Ocidental & 140,1 & 9,4 & 137,4 & 8,4 & 156,4 & 9,2 \\
Hoianda & 59,8 & 3,9 & 74,3 & 4,5 & 81,0 & 4,8 \\
Demais Paises & 292,6 & 19,4 & 342,9 & 20,8 & 335,5 & 19,8 \\
Total & $1,504,3$ & 100,0 & $1.644,9$ & 100,0 & $1.694,5$ & 100,0 \\
\hline
\end{tabular}

Fonte: Boletim mensal do Banco Central do Brasil. Obs : Bancos comerciais e bancos de investimento.

Tabela 3 - Participação dos bancos estrangeiros nos depósitos e empréstimos dos bancos comerciais e múltiplos privados - 1990/91(\%)

\begin{tabular}{c|c|c}
\hline Depósitos e empréstimos & 1990 & 1991 \\
\hline Depósitos & 100,0 & 100,0 \\
Bancos privados nacionais & 79,7 & 80,4 \\
Bancos estrangeiros & 20,3 & 19,6 \\
Empréstimos & 100,0 & 100,0 \\
Bancos nacionais privados & 78,4 & 81,8 \\
Bancos estrangeiros & 21,6 & 18,2 \\
\hline
\end{tabular}

Fonte: Balanço anual 1991 e Balanço anual 1992.

Obs: a) 1990: 177 bancos comerciais e múltiplos privados (142 nacionais e 35 estrangeiros);

b) 1991: 195 bancos comerciais e múltiplos privados (158 nacionais e 37 estrangeiros). 
Um outro indicador apropriado para se medir a internacionalização do sistema financeiro é a estimativa da proporção do passivo externo no passivo bancário total, ou seja, a relação entre empréstimos externos captados para repasse interno (Resolução 63), mais títulos, eurobônus e outros repasses externos, e o total do passivo das instituições financeiras. Constata-se, pela Tabela 4, que não somente para os bancos comerciais e múltiplos, mas também para os bancos de investimento, empresas de arrendamento mercantil ou leasing. Banco do Brasil e BNDES, essa proporção se mostrou significativamente crescente entre junho de 1989 e junho de 1992. Ademais, enquanto na década de 70 houve grande volume de captação via Resolução 63 e linhas de crédito de curto prazo, depois do Plano Collor as captações externas se constituíram mais por commercial papers, eurobônus e outros títulos do mercado de capitais. O segmento de leasing internacional, por exemplo, se apresentou bastante dinâmico no último período, em razão da política creditícia restritiva, da abertura da economia e da extensão dos prazos para arrendamento de bens importados. ${ }^{3}$

Tabela 4 - Participação das obrigações externas

no passivo do sistema financeiro jun/1989 a jun/1992 (\%)

\begin{tabular}{|c|c|c|c|c|c|c|c|}
\hline \multirow[t]{2}{*}{ Sistema financeiro } & \multicolumn{2}{|c|}{1989} & \multicolumn{2}{|c|}{1990} & \multicolumn{2}{|c|}{1991} & 1992 \\
\hline & Junho & Dezembro & Junho & Dezembro & Junho & Dezembro & Junho \\
\hline Bancos comerciais & & & & & & & \\
\hline mú & 11,3 & 19,5 & 11,8 & 14,0 & 13,2 & 17,2 & 26,3 \\
\hline Banco do Brasii & 5,0 & 5,5 & 4,5 & 5,0 & 5,7 & 6,5 & 9,3 \\
\hline BNDES & 10,2 & 9,1 & 9,0 & 11,2 & 9,1 & 9,1 & 7,4 \\
\hline Soc de & & & & & & & \\
\hline mercantil (leasing) & 15,2 & 16,7 & 20,0 & 22,2 & 23,3 & 22,2 & 20,6 \\
\hline Bancos de Investimento & 8,4 & 12,5 & 11,9 & 9,4 & 6,8 & 7.9 & 14,8 \\
\hline
\end{tabular}

Fonte: Boletim mensal do Banco do Brasil (1992a)

Nota: Obrigações externas: empréstimos externos pela Resolução 63, captação externa em titulos e eurobônus e outros empréstimos externos.

A internacionalização se explicita também no ramo de seguros e na destacada expansão de escritórios de representação de bancos estrangeiros no País durante a década de 70 (Baer, 1986, Quadro 12, p. 43). Um dos principais fatores para que isso ocorresse foi a idéia de se instalar nesse período uma unidade off-shore no Rio de Janeiro (Rio-Dólar), ou seja, um centro financeiro com todos os benefícios fiscais e financeiros dos principais centros financeiros internacionais (Baer, 1986, p.42). Além disso, cabe notar que vários bancos estrangeiros têm no Brasil uma importante fonte de lucro, seja atuando diretamente no País seja recebendo juros da divida externa (Baer, 1986, p.52 e) Portella F, 1991, Tab 9, p. 199).

Por outro lado, constata-se que a participação dos bancos brasileiros no exterior, iniciada de forma determinante pelo Banco do Brasil, foi fundamental para o financiamento das exportações e dos investimentos estatais durante a década de 70 (ver Baer, 1986, p. 57). A partir da segunda metade dessa década e do começo da seguinte, vários bancos privados ou estaduais também seguiram o caminho da participação no exterior, tal como já faziam, Banco do Brasil, Real e Banespa 3 Para ilustrar isso, em 1991, as empresas de leasing estrangeiras detinham $34,4 \%$ do valor dos
bens arrendados (ou imobilizado) do mercado (Balanço anual 1992,1992). 
anteriormente. Como descreve Baer (1986, p.61), a partir de uma segunda etapa iniciada em 1979, a atuação dos bancos brasileiros se deu "... não mais para financiar a expansão produtiva, mas para refinanciar a crescente dívida externa". Segundo esse economista, a necessidade de incremento das exportações, a política monetária restritiva interna $e$ o interesse pela instalação de agências ou escritórios em "paraísos fiscais" foram os principais fatores que induziram os grandes bancos privados nacionais a se instalarem no exterior nesse período.

No entanto a crise da dívida externa em 1982 impediu um maior aumento do número de agências externas, na medida em que os bancos estrangeiros deixaram de colocar dinheiro junto aos bancos brasileiros para cobrir linhas de crédito de curto prazo interbancárias e do comércio exterior. $\mathrm{O}$ acordo estabelecido com o Fundo Monetário Internacional (FMI) ao final de 1982, em meados de 1983 já não era cumprido, refletindo-se numa aguda redução das reservas internacionais como resultado da perda do saldo das linhas de crédito de curto prazo das agências externas. ${ }^{4}$ Posteriormente, as negociaçōes com os bancos credores e o FMI prosseguiram até 1986, e apesar do Brasil ter obtido alguma melhoria nos spreads (taxas de risco) e nos prazos de carência das amortizações, a verdade é que se verificou uma abrupta retração dos empréstimos voluntários dos bancos estrangeiros ao País. Esse quadro culminou com a decretação da moratória pelo Brasil em fevereiro de 1987, o que levou os bancos americanos a reconhecer, pela primeira vez, as perdas com as dividas dos paises do Terceiro Mundo (ver Carneiro dos Santos, 1991). Somente com o acordo da dívida de 1988 seria dado o primeiro passo para a redução do risco cambial das agências externas, com o estabelecimento do pagamento dos débitos do País junto aos bancos brasileiros.

Por sua vez, as moratórias de 1983, 1987 e 1989 parecem ter sido um fator importante para explicar o avanço do capital estrangeiro no sistema financeiro nacional no período mais recente. Como afirma José R.M. de Barros, "... Os credores externos, percebendo que não receberiam seus créditos a curto prazo, decidiram reforçar sua participação no Brasil para administrar seus próprios ativos em cruzados e eles iniciaram um processo de mudança de natureza do sistema nacional" (GM, 14/09/90). O acordo da dívida de 1988 estabeleceu condicionalidades com uma reforma financeira orientada pelo Banco Mundial, de âmbito liberal e que, de fato, foi em parte implantada, com a criação do banco múltiplo. Por fim, o acordo propiciou elevados lucros aos bancos estrangeiros, com a conversäo da dívida exterior em investimentos de risco sem a apropriação pelo País do deságio do mercado secundário (Portella $F^{\circ}, 1991$, p.184-185 e Munhoz, 1989).

\section{O BANCO MÚLTIPLO E A ABERTURA DA ECONOMIA}

Com a instituição do banco múltiplo em 1988 tinha-se uma expectativa inicial de um elevado risco de falência de instituições financeiras que não tivessem experiência no ramo e não atendessem às exigências de capitalização. ${ }^{5}$. No entanto, depois de mais de três anos a realidade é que isso não se verificou (ver,

\footnotetext{
4 Note-se que, efetivamente, a dívida bancária com os bancos brasileiros no exterior representa um risco cambial, na medida em que "as autoridades brasileiras tudo farão para evitar uma crise de liquidez das agências dos bancos brasileiros no exterior"(ver Souza, 1985, p.153, nota de rodapé).

${ }_{5}$ Estimadas em cerca de US $\$ 15$ milhóes para o patrimônio de um banco estrangeiro de cinco agências.
} 
GM, 31/03/92), ou seja, a redução dos custos da informatização com a liberalização das importações e a abertura da economia permitiram que novas e pequenas instituições tivessem acesso à modernização e ao mercado financeiro. Além do mais, grandes empresas multinacionais não-financeiras, mesmo com a extinção do overnigh para pessoas fisicas e jurídicas não-financeiras em janeiro de 1991, continuaram a ter acesso à ciranda financeira através de seus próprios bancos, nas aplicações em Certificados de Depósitos Interbancários (CDIs). Os bancos estrangeiros, em particular, se utilizaram mais da bipartição, como, no caso do Citibank, que tem pedido ao Banco Central para se transformar em banco múltiplo a partir de uma financeira ou, do Lloyds, que se bipartiu em banco múltiplo a partir de uma distribuidora (ver, GM, 31/03/92).

Uma das críticas que se fazem à reforma bancária de 1988, que criou o banco múltiplo, é o fato de não se ter estabelecido nenhum tipo de limite mínimo de alavancagem de longo prazo, ou seja, de aplicações de longo prazo, essencial para a retomada do crescimento (IESP/Fundap, 1990, p 52). A resolução 1.556 de dezembro de 1986 apenas limita a proporção de recursos de terceiros sobre os recursos próprios em no máximo 15 vezes $^{6}$ e a relação entre o ativo permanente e o patrimônio líquido em no máximo $90 \%$. A desregulamentação do banco múltiplo propiciada pela Resolução $1.524,{ }^{7}$ fez com que várias instituições financeiras estrangeiras entrassem nos segmentos de caderneta de poupança, crédito ao consumo, crédito imobiliário, assim como aumentassem a participação no cobiçado segmento de câmbio. Além disso, caso haja a regulamentação do Projeto de Lei do Artigo 192 da Constituição, haverá maior abertura do mercado brasileiro aos bancos estrangeiros. Uma das razões para isso é que com a garantia de reciprocidade dada pelo Brasil, mais bancos estrangeiros deverão se instalar aqui, em virtude da crescente participação que os bancos brasileiros assumem em países como EUA, Europa Ocidental e Japão.

Por outro lado, as aberturas comercial e financeira adotadas a partir do Governo Collor tiveram atuação decisiva para a internacionalização financeira Ou seja, a liberalização gradativa da política cambial e das importações, assim como autorização para o sistema bancário captar commercial papers (Resolução 1.743) tiveram efeito especial para esse processo. Entre o final de 1990 e meados de 1991, foram regularizados os pagamentos dos juros atrasados da dívida externa e dos encargos externos do setor privado e das empresas estatais (Relatório anual do Banco Central do Brasil, 1991), assim como passou-se a incentivar mais as exportações como meio de se neutralizar a recessão interna.

Com o início da devolução dos cruzados novos em agosto, o Banco Central elevou as taxas de juros visando conter a pressão da liquidez sobre o consumo e os preços (Burle, 1992), o que, juntamente com a recessão e liquidez internacionais, acabou atuando indiretamente para um grande afluxo de capitais de curto prazo para o Pais Além disso, no final de 1991, o Governo adotou várias medidas de estímulo ao investimento direto externo, como extinção do imposto de renda suplementar sobre as remessas de lucros e dividendos, com vigência a partir de

\footnotetext{
${ }^{6}$ No caso dos bancos estaduais e estrangeiros é maior, pois não se inclui repasses oficiais e externos.

${ }^{7}$ Vale acrescentar que o Banco Central exige um mínimo de duas carteiras, sendo pelo menos uma de banco comercial ou de banco de investimento
} 
1993. Na captação em eurobônus, pex, os principais fatores que explicam a participação decisiva do sistema financeiro são "... a sua internacionalização, a carteira de aplicações mais diversificada dos bancos do que às empresas nãofinanceiras (permitindo a diluição dos riscos associado aos eurobônus) e as elevada taxas de juros internas já assinaladas" (Burle, 1993, p 109).

\section{OS BANCOS ESTRANGEIROS NO PAíS}

Em 1991, a participação dos dez maiores bancos comerciais e múltiplos estrangeiros em captação de depósitos ${ }^{8}$ no total dos depósitos captados pelos bancos comerciais e múltiplos estrangeiros foi de $80,6 \%$, o que indica uma expressiva concentração. Neste mesmo ano, os bancos comerciais e múltiplos estrangeiros registraram maior proporção de crédito em liquidação relativamente ao patrimônio líquido real do que os bancos privados nacionais, o que pode ter levado as instituições financeiras estrangeiras a diminuir as operações de crédito em relação a 1990, enquanto que com as instituições privadas nacionais ocorreu o oposto (Tab 5 e 6). Além disso, os bancos estrangeiros se mostraram menos ativos nas captações em depósitos (crescimento real dos depósitos), apresentaram uma proporção menor de recursos próprios (razões patrimônio líquido/passivo real) e menor taxa de rentabilidade (lucro líquido/patrimônio líquido) do que os congêneres nacionais privados (Tab. 5 e 6 ).

Tabela 5 - Indicadores contábeis dos bancos comerciais estrangeiros -1991 (\%)

\begin{tabular}{|c|c|c|c|c|c|}
\hline $\begin{array}{l}\text { Bancos/ País } \\
\text { controlador }\end{array}$ & $\begin{array}{l}\text { Crescim } \\
\text { real dos } \\
\text { depósitos }\end{array}$ & $\begin{array}{l}\text { Créditos em } \\
\text { liquid./ Patr. } \\
\text { liq. real }\end{array}$ & $\begin{array}{l}\text { Crescimento } \\
\text { real das oper } \\
\text { de crédito }\end{array}$ & $\begin{array}{l}\text { Patrim líq } \\
\text { real/ Passi- } \\
\text { vo real }\end{array}$ & $\begin{array}{l}\text { Lucro liq. } \\
\text { Patr liq. } \\
\text { real }\end{array}$ \\
\hline$\overline{\text { Citibank (EUA) }}$ & 36,1 & 8,8 & $-51,8$ & 6,0 & $\overline{0,2}$ \\
\hline Lloyds (Inglaterra) & 45,8 & 9,3 & $-28,5$ & 6,8 & 0,4 \\
\hline Boston (EUA) & 19,4 & 4,6 & 21,5 & 6,2 & 2,5 \\
\hline Holandês (Holanda) & 145,9 & 4,4 & 52,7 & 6.4 & $-20,4$ \\
\hline Morgan (EUA) & 43,0 & 0,0 & $-86,8$ & 4,5 & 16,4 \\
\hline ING (ex-NMB)(Holanda) & 185,2 & 0,7 & $-64,3$ & 6,3 & $-16,2$ \\
\hline BEAL (Bélgica) & $-38,2$ & 5,2 & $-36,3$ & 12,5 & 1,5 \\
\hline Deutsche (Alemanha) & $-4,3$ & 1,3 & $-39,9$ & 15,5 & $-8,3$ \\
\hline Deutsch (Alemanha) & 10,0 & 0,0 & 7,5 & 15,6 & 2,1 \\
\hline Unión (Venezuela) & 30,1 & 0,7 & 17,1 & 18,2 & 12,2 \\
\hline España (Espanha) & 0,7 & 56,3 & 16,2 & 20,9 & 1,3 \\
\hline Santander (Espanha) & $-34,2$ & 0,0 & $-53,4$ & 14,3 & $-23,0$ \\
\hline Financial (Portugal) & 83,9 & 3,3 & $-38,4$ & 48,0 & $-2,2$ \\
\hline Centrobanco (Espanha) & 6,8 & 16,5 & 124,0 & 75,2 & $-10,2$ \\
\hline Hispano (Espanha) & $-15,1$ & 0,0 & $-25,2$ & 32,0 & 14,4 \\
\hline Total 18 bancos con & 8,4 & 6,5 & 26,9 & 7,7 & $-2,1$ \\
\hline Total: 12 banc. com priv. nac. & 73,7 & 1,9 & 32,3 & 12,4 & 6,9 \\
\hline
\end{tabular}

Fonte: Balanço anual 1992 (1992) Obs: 1 - Patrimônio liquido real: patrim.liq $(+)$ resultados exerc futuros $(-)$ ativo diferido (-) desp exerc seguinte; 2 - Passivo real: pas circulante $(+)$ exigivel a longo prazo $(+)$ patrim liq real e; 3 - Cresc. real dos depósitos e dos empréstimos em relação a 1990 (Deflator:BTN/IPC).

8 Os bancos são: Citibank, Lloyds, BFB, Sudameris, Boston, Chase, CCF, Holandês Unido, Montrealbank e Central Motors, dentro de um total de 37 bancos (Balanço Anual 1992, 1992). 
Tabela 6 - Indicadores contábeis dos bancos comerciais estrangeiros -1991 (\%)

\begin{tabular}{l|r|r|r|r|r}
\hline \multicolumn{1}{c|}{$\begin{array}{c}\text { Bancos/ } \\
\text { Pais controlador }\end{array}$} & $\begin{array}{c}\text { Crescimento } \\
\text { real dos } \\
\text { depósitos }\end{array}$ & $\begin{array}{c}\text { Créditos em } \\
\text { liquidação/ } \\
\text { Patr. liq. real }\end{array}$ & $\begin{array}{c}\text { Crescimento } \\
\text { real das oper } \\
\text { de crédito }\end{array}$ & $\begin{array}{c}\text { Património } \\
\text { liquido real } / \\
\text { Passivo real }\end{array}$ & $\begin{array}{c}\text { Lucro liq.l } \\
\text { Patr. liq } \\
\text { real }\end{array}$ \\
\hline BFB (França) & 33,2 & 7,1 & 16,8 & 8,7 & 1,6 \\
Sudameris (França) & 0,4 & 3,8 & $-30,6$ & 10,5 & 3,2 \\
Chase (EUA) & 67,2 & 1,1 & $-29,2$ & 8,9 & 4,4 \\
CCF (França) & 134,9 & 0,0 & 36,9 & 7,5 & 12,1 \\
Montrealbank (Canadá) & 20,8 & 2,1 & $-40,4$ & 13,3 & 1,2 \\
General Motors (EUA) & $-3,1$ & 0,4 & 5,2 & 10,7 & 0,2 \\
Tokyo (Japão) & 10,5 & 18,9 & 15,6 & 11,9 & 3,9 \\
Sumitomo(Japäo) & 12,8 & 1,6 & $-3,0$ & 15,8 & 0,8 \\
Mitsubishi (Japäo) & $-64,8$ & 12,2 & $-55,3$ & 28,1 & $-47,0$ \\
Gulfinvest (EUA) & $1,972,4$ & 0,0 & 269,7 & 7,6 & 4,8 \\
Continental (EUA) & 15,8 & 0,0 & 94,2 & 14,5 & 40,2 \\
Multi Banco (EUA) & $-53,9$ & 0,0 & $-16,2$ & 13,5 & 12,7 \\
Royal Bank (Canadá) & $-45,7$ & 0,6 & $-14,1$ & 11,0 & 7,2 \\
Boston (EUA) & 868,2 & 0,0 & $-18,2$ & 8,4 & 45,8 \\
Total: 19 banc. mültip. estrang & 10,5 & 4,6 & $-14,1$ & 11,0 & 3,1 \\
Total: 146 banc.mültip.priv.nac. & 27,3 & 2,3 & 10,3 & 16,1 & 9,6 \\
\hline
\end{tabular}

Fonte: Balanço anual 1992 (1992) Obssenvações: as mesmas da Tabela 5

Já a Tab. 7 apresenta outros indicadores contábeis dos bancos estrangeiros para 1989 e 1990, como a proporção entre o ativo circulante e o passivo circulante (liquidez corrente), a proporção entre o ativo permanente e o patrimônio líquido (imobilização ou inverso da capitalização) e as proporções das receitas cambiais nas receitas operacionais e das despesas de pessoal nas despesas operacionais. Verifica-se, p.ex, que em 1990 os bancos comerciais e múltiplos estrangeiros elevaram as receitas de câmbio e as despesas de pessoal no total das receitas e despesas operacionais, respectivamente, em relação ao ano anterior.

Tabela 7 - Outros indicadores contábeis dos bancos estrangeiros - 1989/1990 (\%)

\begin{tabular}{|c|c|c|c|c|c|c|c|c|}
\hline \multirow[t]{2}{*}{ Bancos } & \multicolumn{2}{|c|}{$\begin{array}{l}\text { Ativo circulante/ } \\
\text { Passivo circulante }\end{array}$} & \multicolumn{2}{|c|}{$\begin{array}{c}\text { Ativo permanentel } \\
\text { Património } \\
\text { Ifquido }\end{array}$} & \multicolumn{2}{|c|}{$\begin{array}{c}\text { Receitas } \\
\text { Cambiais/ } \\
\text { Receitas operac. }\end{array}$} & \multicolumn{2}{|c|}{$\begin{array}{l}\text { Despesas de } \\
\text { pessoal/ Desp } \\
\text { operac. }\end{array}$} \\
\hline & 1989 & 1990 & 1989 & 1990 & 1989 & 1990 & 1989 & 1990 \\
\hline Sumitomo & 130,1 & 116,3 & 11,1 & 11,7 & 0,2 & 0,5 & 0,6 & 0,9 \\
\hline Unión & 107,7 & 108,3 & 36,2 & 34,3 & 2,9 & 5,6 & 0,3 & 0,9 \\
\hline Financial & 301,7 & 142,7 & 5,6 & 5,2 & 0,5 & 1,7 & 3,5 & 5,8 \\
\hline NMB & 114,9 & 102,6 & 9,8 & 8,2 & 1,3 & 11,3 & 1,5 & 3,1 \\
\hline Santander & 120,9 & 111,3 & 7,5 & 7,3 & 2,5 & 8,4 & 1,9 & 3,4 \\
\hline Hispano & 152,0 & 130,6 & 13,6 & 10,8 & 3,6 & 7,1 & 3,5 & 8,0 \\
\hline La Nación & 116,6 & 51,3 & 37,4 & 82,8 & 3,7 & 2,6 & 3,8 & 2,9 \\
\hline Mitsubishi & 96,2 & 89,8 & 83,6 & 57,3 & 0,4 & 1,0 & 1,4 & 2,7 \\
\hline Boston & 99,9 & 101,2 & 77,2 & 87,9 & 0,4 & 1,3 & 2,8 & 4,2 \\
\hline Tokyo & 110,5 & 110,6 & 44,9 & 36,8 & 0,5 & 1,6 & 0,8 & 1,9 \\
\hline Sudameris & 100,5 & 99,2 & 75,1 & 79,2 & 1,6 & 3,3 & 2,9 & 5,9 \\
\hline BEAl. & 105,6 & 106,6 & 50,8 & 72,7 & sd & sd & sd & sd \\
\hline Lloyds & 44,5 & 109,8 & 48,6 & 74,1 & 1,8 & 3,4 & 2,3 & 3,8 \\
\hline Deutsch & 120,2 & 104,8 & 34,9 & 42,9 & 16,7 & 43,9 & 1,8 & 2,1 \\
\hline BFB & 101,9 & 100,1 & 71,1 & 80,4 & 1,4 & 3,2 & 1,8 & 3,9 \\
\hline Total & 95,5 & 102,8 & 56,6 & 65,6 & 1,4 & 3,6 & 2,7 & 3,9 \\
\hline
\end{tabular}

Fonte: Revista Bancária Brasileira (1991a) Obs.: 1 - Indice de liquidez corrente: ativo circulantel passivo circulante; 2 Índice de imobilização: ativo permanente/ patrimônio liquido e; 3 - sd: sem dado. 
No periodo 1990/1992, o Citibank procurou se ajustar através da recuperação das dívidas do setor público, do corte de pessoal, da venda de ativos e da diversificação operacional para novos segmentos, como os de pessoa física (private banking) e de underwritting. ${ }^{9}$ Com relação a redução no quadro de pessoal, de 5.000 para 3.000 funcionários, entre 1987 e 1991, como esclarece o principal executivo do Citibank, Álvaro de Souza, em entrevista ao jornal Gazeta Mercantil (ver, GM, 08/10/92), ". Você acha que esses 2000 funcionários estavam sobrando? Não, eles trabalhavam em coisas que hoje não dão mais dinheiro", ou seja, nas atividades do varejo que propiciavam os ganhos bancários na época da inflação $e$ da ciranda financeira.

O Lloyds foi atingido pelas inadimplências do setor público e do setor privado (concordatas das empresas privadas Cevekol, Riachuelo e Sibisa, por exemplo) em razão das altas taxas de juros de crédito no final de $1990 \mathrm{e}$, por isso, teve que fazer provisões para esses créditos, o que determinou uma proporção de $9,3 \%$ de créditos em liquidação sobre o patrimônio líquido (ver, Tabela 5). $O$ banco reduziu a estrutura de agências e o quadro de profissionais dos niveis médios e da alta gerência, adotou a seletividade da clientela e se concentrou no crédito às grandes empresas Já o BFB foi bastante atingido pela Lei 8.200 em 1991 - reduzindo o lucro liquido com o aumento das despesas de depreciação $e$ insuflando o patrimônio líquido com a correção monetária adicional - pois, conforme se verifica pela Tabela 7, em 1989 e 1990 foi um dos menos capitalizados, ou seja, que registrou uma das menores proporções de ativos permanentes sobre o patrimônio liquido $(71,1 \%$ e $80,4 \%$, respectivamente). No entanto, se destacou nas captações de depósitos a prazo (CDBs), nos repasses do Finame/BNDES, nas captações em fundos de renda fixa e de ações, entre outros filões do mercado.

o Sudameris é um consórcio de bancos estrangeiros, com $75 \%$ das ações pertencentes a bancos franceses, e foi atingido pela defasagem na correção monetária em relação à inflação das debêntures da Siderbrás a partir de 1991, e pelo atraso da União no pagamento desses papéis, o que determinou a realização de provisão para esses créditos. No entanto, esse banco acabou compensando, de certa forma, a rentabilidade (de 3,2 \% em 1991, ver Tab.6), com a atuação nas áreas de private banking e de crédito às grandes empresas. $O$ Banco de Boston é uma instituição que se antecipou ao bloqueio monetário de março de 1990, pois desde 1986 vinha efetuando um programa de expansão dos aportes de capital da matriz, e que incluiu investimentos em informática, treinamento de pessoal, resultando no aumento de agências de 6 em 1988 para 24 em 1991 (Tab.8). Além disso, se dedicou à captações pelo fundo de renda fixa com hedge no mercado futuro de taxas de juros (CDls futuros) e ao financiamento do comércio exterior e das grandes empresas. Por sua vez, enquanto o Chase americano se especializou no atacado, no financiamento do comércio exterior e no private banking, o CCF francês se concentrou no financiamento do comércio exterior, no atendimento às grandes empresas (corporate bank) e nas captações pelos fundos de investimentos. O Banco Holandês Unido incorporou a financeira Aymoré, se transformou em banco

${ }^{9}$ Enquanto o segmento de pessoa física (private banking) abrange as classes alta e média-alta, 0 segmento underwritting engloba fundos de investimento, compra e venda de ações, lançamento de ações etc. 
múltiplo, e vem introduzindo gradativamente, nas agências desta última, as atividades do private banking, do interbancário e do mercado flutuante de câmbio:

Tabela 8 - Rede de agências dos bancos comerciais e múltiplos estrangeiros - 1990/1992 ${ }^{1}$

\begin{tabular}{|c|c|c|c|c|c|c|c|}
\hline Banco & Agênc. & Banco & Agênc. & Banco & Agênc. & Banco & Agênc. \\
\hline Sudameris & 97 & Tokyo & 12 & ING & 3 & Deutsch & 1 \\
\hline BFB & 61 & BEÁL & 8 & Financial & 3 & España. & 1 \\
\hline Holandês/Aymoré & 30 & GeneralMotors & 7 & Multi & 3 & Royal Bank & 1 \\
\hline Boston & 24 & Montrealbank & 7 & Chase & 3 & Continental & 1 \\
\hline Citibank & 22 & $\mathrm{CCF}$ & 5 & Morgan & 2 & Gulfinvest & 1 \\
\hline Mitsubishi & 18 & Sumitomo & 4 & Santander & 1 & Centrobanico & 1 \\
\hline Lloyds & 16 & Deutsche & 3 & Hispano & 1 & Unión & 1 \\
\hline Total & & & & & & & 337 \\
\hline
\end{tabular}

Nota: ${ }^{1}$ Por falta de informaçőes os dados não são de um mesmo período de tempo.

Fonte: Revista Bancária Brasileira (1990, 1991a, 1991b) e jornal Gazeta Mercantil, diversas edições.

Apesar de os bancos múltiplos japoneses (Tokyo, Sumitomo e Mitsubishi, ver Tabela 6) não terem tido expressão importante em captação de depósitos em 1991, tais instituições se destacaram em empréstimos outorgados e valor patrimonial das agência instaladas no País (Balanço anual 1992, 1992) Conforme notado anteriormente, vários bancos privados possuem uma composição acionária repartida igualitariamente entre o capital estrangeiro $(50 \%)$ e o capital nacional $(50 \%)$ como Multiplic, BBA, ABC/Roma, Banco Brasileiro Iraquiano (BBI), Credibanco e Dime (ver Tabela 9). São instituições financeiras criadas, em grande parte, ao final dos anos 80 , e que têm uma certa importância no mercado financeiro. Além disso, vários bancos múltiplos privados nacionais possuem participação acionária minoritária do capital estrangeiro, conforme se verifica na Tabela 9 . 0 Banco América do Sul, por exemplo, apresenta $25 \%$ das ações pertencentes ao Fuji Bank do Japão, tem alta influência japonesa nas diretrizes administrativas, se destaca no atendimento da colônia japonesa em São Paulo e na transferência de recursos de brasileiros residentes no Japão para o Brasil.

Tabela 9 - Participação estrangeira no

capital dos bancos comerciais mültiplos privados ( $\mathrm{Em} \%$ do capital social)

\begin{tabular}{|c|c|c|c|c|c|c|c|}
\hline Bancos & $\%$ & Bancos & $\%$ & Bancos & $\%$ & Bancos & $\%$ \\
\hline Citibank & 100 & $\mathrm{CCF}$ & 100 & Santander & 100 & Dime & 50 \\
\hline Holandês & 100 & Centrobanco & 100 & Deutsche & 100 & Norchem & 48,9 \\
\hline Lloyds & 100 & Sumitomo & 100 & Deutsch & 100 & Inter-Atlântico & 47,3 \\
\hline $\begin{array}{l}\text { Boston } \\
\text { La Nación }\end{array}$ & 100 & $\begin{array}{l}\text { Tokyo } \\
\text { Província de }\end{array}$ & 100 & General Motors & 100 & Banco Cidade & 45 \\
\hline Argentina & 100 & Buenos Aires & 100 & Chase & 99,1 & Sogeral & 36,8 \\
\hline Financial & 100 & Sudameris & 100 & Mitsubishi & 84,9 & Unibanco & 26,5 \\
\hline BEAL & 100 & Continental & 100 & Multiplic & 50 & América do Sul & 25 \\
\hline $\begin{array}{l}\text { Unión de bancos } \\
\text { del Uruguay }\end{array}$ & 100 & $\begin{array}{l}\text { Rep Oriental } \\
\text { del Uruguay }\end{array}$ & 100 & ABC Roma & 50 & Fininvest & 21.7 \\
\hline Unión & 100 & Montrealbank & 100 & BBA & 50 & Itaú & \\
\hline España & 100 & Multi Banco & 100 & BBI & 50 & Bozano Simonsen & 6,2 \\
\hline Hispano & 100 & Royal Bank & 100 & Credibanco & 50 & & \\
\hline
\end{tabular}

Fonte: Baer (1986, p.27) e Rev Bancaria Brasileira (1990, 1991 e 1991a). Obs.: a) Refere-se ao capital detido por residentes no exterior, cf. dados de balanço e; b) Os dados são na maioria dos bancos, de jun. e dez. 1990. 
Em sintese, os bancos estrangeiros têm funcionários altamente qualificados e treinados e por isso, geralmente, apresentam menor rotatividade de mão-de-obra do que os bancos privados nacionais (Exame, 24/06/92). Contudo, entre 1990 e 1992, as instituições financeiras estrangeiras também cortaram pessoal e se ajustaram, não somente em razão do bloqueio monetário, da contenção monetária e da extinção do overnight ao nível interno, mas também pela restruturação administrativa que se verificou no exterior, como nos EUA, com a inadimplência dos titulos de alto risco (junk-bonds") e dos empréstimos imobiliários nesse pais.

\section{OS BANCOS BRASILEIROS NO EXTERIOR}

No período 1990/1992, a atuação externa dos bancos brasileiros também foi marcante. Em 1990 o risco cambial das agências externas esteve inicialmente elevado em virtude da retenção dos pagamentos da dívida externa, o que fez o Conselho Monetário Nacional (CMN) suspender a autorização para abertura de agências no exterior. $O$ Governo não pagou as tranches trimestrais acertadas no acordo de 1988 no total de US $\$ 1,8$ bilhöes com as agências externas, o que obrigou os bancos brasileiros a captar recursos no interbancário internacional a juros elevadas, para cobrir os créditos de médio e longo prazo com o Brasil que, ao final de 1989 , somavam US $\$ 6,4$ bilhões [Diário do Com Indústria (DCI), 09/10/90].

No entanto, em outubro, o País acertou os pagamentos dos atrasados com os bancos brasileiros no exterior em três parcelas no total de US $\$ 450$ milhões, fixou o fim da compulsoriedade dos bancos estrangeiros em atender às linhas de comércio exterior (Projeto 3) e interbancário (Projeto 4) para a partir de abril de 1991 e estabeleceu um programa de capitalização das agências externas para $1990 \mathrm{e}$ 1991. A Res 1.754 do CMN determinou que as agências dos bancos brasileiros no exterior fossem capitalizadas ao nivel de $25 \%$ dos seus portfólios com aqueles créditos, até o máximo de $100 \%$ do patrimônio liquido. Além disso, ficou estipulada a dispensa do aumento do capital da matriz pelo correspondente ao das dependências externas, e o benefício das remessas poder ser pelo câmbio oficial (câmbio livre), sem a compensação cambial em ouro (ver, DCl, 09/10/90). Isto significa que os bancos não precisaram comprar ouro no mercado paralelo e vender ao Banco Central no montante das remessas, evitando perdas financeiras.

O que se constatou foi que todos bancos brasileiros com dependências externas remeteram os capitais necessários como o usufruto do benefício de não precisar comprar ouro para depósito na autoridade monetária, ou seja, segundo o Banco Central foram remetidos US $\$ 224$ milhões em 1990 e US\$ 651 milhōes em 1991, dentro do programa de capitalização (Rel do Bacen, 1991b, p.107). Assim como as linhas de crédito de curto prazo aumentaram em vez de diminuírem, em razão da redução das taxas de juros (Libor) e da recessão nos países industrializados. Como resultado disso e da regularização parcial dos demais compromissos da dívida externa, em julho de 1991 o Banco Central voltou a analisar pedidos para a instalação de agências e escritórios no exterior. Desse mês em diante, verificou-se que pelo menos quatro novos bancos ${ }^{10}$ passaram a ter agênçias ou escritórios no

${ }^{10}$ Banorte, Garantia, BBA e Multiplic, sendo os dois últimos com $50 \%$ de participação de capital estrangeiro, conforme se verificou pela Tabela 9 . 
exterior, além dos próprios pedidos dos bancos que já possuíam dependências externas, principalmente para o "paraíso fiscal" de Grand Cayman (Tab.10 e 11).

Especificamente ao Banco do Brasil, vale notar a importância que essa instituição tem na rolagem da divida externa e no financiamento do comércio exterior. Além de possuir a mais vasta rede de agências e escritórios no exterior como se verifica na Tab.10, esse banco conta com três subsidiárias, duas coligadas e cinco participações acionárias. ${ }^{11}$ Ademais, vem expandindo os postos de atendimento no Japão, visando atender os brasileiros residentes nesse país, conta com inúmeros bancos correspondentes no exterior $\mathrm{e}$, enfim, vários fatores que o tornam o líder no volume da carteira de câmbio.

Tabela 10 - Número de dependências externas dos bancos brasileiros - 1992

\begin{tabular}{l|c|l|c|l|c}
\hline \multicolumn{1}{c|}{ Bancos } & Dependências & \multicolumn{1}{c|}{ Bancos } & Dependéncias & Bancos & Dependências \\
\hline Banco do Brasil & 48 & Itaú & 3 & Banrisul & 1 \\
Real & 33 & Mercapaulo & 3 & Banerj & 1 \\
Banespa & 18 & Unibanco & 3 & Noroeste & 1 \\
Banestado & 9 & Safra & 3 & Multiplic & 1 \\
Nacional & 7 & BCN & 2 & Garantia & 1 \\
Bamerindus & 4 & Itamarati & 2 & Banorte & 1 \\
Bradesco & 3 & Bandeirantes & 2 & BBA & 1 \\
Total & & & & Econômico & 1 \\
\hline
\end{tabular}

Fonte: Revista Bancária Brasileira (1990, 1991, 1991a) e Gazeta Mercantil (Balanço dos bancos)

Obs:: a) Inclui agências, escritórios de representação, subsidiárias e dependências controladas no exterior; b) O Banco do Brasil tem 27 agéncias, 13 escritórios e 3 subsidiárias integrais. Considera-se também cinco participações acionárias, o que perfaz o total de 48 dependências

O Banespa recebeu autorização em dezembro de 1989 do CMN para instalar novos escritórios de representação em Bruxelas, Hong-Kong e Moscou e para transformar o escritório de Washington em agência. Além do mais, dentro de uma restruturação seguida a partir de 1990, fechou a agência de São Francisco, e com isso, transferiu US\$ 16 milhões para instalar uma subsidiária integral em Luxemburgo. Nesse país, o banco passou a contar com 15 funcionários, que são também acionistas, e a usufruir do sigilo bancário, da baixa tributação, da inexistência do compulsório sobre depósitos e de regras flexiveis de alavancagem (GM, 27/11/92), propiciando o fácil acesso dos exportadores brasileiros ao mercado europeu. Em síntese, ao final de 1992 o Banespa contava com 18 dependências no exterior, incluindo agências, escritórios e uma subsidiária (Tab.10).

Entre os bancos privados, o Real é o mais tradicional e o que se destaca por possuir a maior rede de agências e escritórios no exterior (ver Tabela 10). Vale notar que o banco conta com várias subsidiárias externas, com destaque para a

11 As três subsidiárias são: Banco do Brasil A. G. em Viena, Áustria; Brasilian American Bank (BAMB), em Grand Cayman e; BB Leasing Company Lida, em Grand Cayman. As duas coligadas são: o Banco Brasileiro Iraquiano (BBI), e sua subsidiária Seguradora Brasileira-Iraquiana (SBI) no Rio de Janeiro; e European Brazilian Bank (Eurobraz), em Londres (esta, em processo de liquidação). $\mathrm{E}$ as cinco participações acionárias são: o Arlabank International $\mathrm{E}$. $\mathrm{C}_{\text {. }}$ Manama, Bahrain; Banco Latinoamericano de Exportaciones SA (Bladex), Panamá; Banque Árabe et Internationale D'Investissement, Paris, França; Bai i Holdings, Luxembugo; Euro-Latinamerican Bank plc, Londres, Inglaterra e; Export Credit Insurance Corporation of Singapore (ECICS). 
América Latina e os Estados Unidos (ver, Baer, 1986, p. 57) ${ }^{12}$ Com relação aos demais bancos privados e alguns estaduais, conforme já visto, somente a partir do final da década de 70 que começaram a instalar dependências no exterior. Verificase pela Tabela 11 que nos anos 80 , principalmente depois da crise da dívida externa de 1982, aumentou substancialmente o investimento brasileiro no exterior, refletindo diretamente a expansão externa dos bancos brasileiros nos "paraisos fiscais", não somente das instituições financeiras novas, como também das já tradicionais, ou seja, Banco do Brasil, Banespa e Real. ${ }^{13}$

Tabela 11 - Investimentos brasileiros no exterior por principais países - 1965/1991 (US\$ milhões)

\begin{tabular}{|c|c|c|c|c|c|c|c|c|c|c|c|c|}
\hline \multirow[b]{2}{*}{ Países } & \multirow{2}{*}{$\begin{array}{c}\text { Estoq } \\
\text { acum } \\
65 / 81\end{array}$} & \multicolumn{10}{|c|}{ Fluxos } & \multirow{2}{*}{$\begin{array}{l}\text { Estoq. } \\
\text { acum. } \\
65 / 91\end{array}$} \\
\hline & & 1982 & $19 \overline{8}$ & 1984 & 1985 & 1986 & 1987 & 1988 & 1989 & 1990 & 1991 & \\
\hline $\begin{array}{l}\text { Ant. } \\
\text { Holandesas }\end{array}$ & 53,1 & 23,4 & 0,4 & 0,0 & 0,0 & 0,0 & 0,0 & 0,0 & 0,0 & 0,0 & 0,0 & 78,9 \\
\hline Argentina & 41,5 & 30,5 & 0,0 & 0,2 & 2,0 & 0 & 0,2 & 0,3 & 1,8 & 1,1 & 7,9 & 85,3 \\
\hline Bahamas & 3,3 & 35,0 & 0,0 & 0,0 & 0,8 & 0,0 & 0,0 & 0,0 & 0,0 & 0,0 & 0,0 & 39,1 \\
\hline Bermudas & 3,0 & 0,0 & 0,0 & 0,0 & 0,0 & 40,1 & 0,0 & 0,0 & 0,0 & 0,0 & 0,3 & 43,4 \\
\hline Bolivia & 6,5 & 15,1 & 0,0 & 0,0 & 0,0 & 0,0 & 0,0 & 0,0 & 0,0 & 0,0 & 0,0 & 21,6 \\
\hline Grand Cayman & 18,7 & 8,9 & 18,4 & 36,1 & 0,1 & 32,1 & 51,9 & 45,5 & 216,8 & 168,6 & 766,5 & $1,363,4$ \\
\hline Chile & 21,6 & 34,8 & 0,3 & 0,0 & 0,3 & 0,0 & 2,2 & 2,1 & 0,1 & $-0,4$ & $-6,9$ & 54,1 \\
\hline EUA & 455,9 & 84,0 & 17,4 & 20,9 & 75,3 & 56,4 & 34,2 & 54,9 & 23,6 & 104,0 & 129,6 & $1.056,4$ \\
\hline França & 19,5 & 0,0 & 2,7 & 0,0 & 0,0 & 0,0 & 0,1 & 0,0 & 0,0 & 0,0 & 0,0 & 22,3 \\
\hline Luxemburgo & 17,0 & 0,0 & 0,0 & 0,0 & 0,0 & 0,0 & 0,0 & 0,0 & 1,0 & 3,5 & 0,0 & 21,5 \\
\hline Panamá & 5,2 & 17,8 & 0,4 & 0,0 & 1,0 & 0,0 & 0,1 & 1,0 & 0,0 & 0,0 & 0,0 & 25,6 \\
\hline Para & 37,3 & 17,1 & 1,4 & 0,0 & 0,0 & 0,2 & 0,0 & 0,0 & 0,0 & 0,8 & 1,5 & 58,3 \\
\hline Ports & 5,9 & 0,0 & 0,0 & 0,0 & 0,1 & 0,6 & 0,4 & 0,1 & 63,5 & 39,8 & 29,7 & 140.1 \\
\hline ha Ocid. & 14,3 & 0,6 & 0,0 & 0,1 & 0,2 & 0,3 & 2,2 & 0,2 & 0,1 & 0,0 & 30,5 & 48,4 \\
\hline Ingla & 35,1 & 3,8 & 2,9 & 3,2 & 0,4 & 1,3 & 1,4 & 42,3 & 5,4 & 130,0 & 12,1 & 237,9 \\
\hline Urug & 19,2 & 16,9 & 0,0 & 0,0 & 0,0 & 0,0 & 0,0 & 0,0 & 0,1 & 0,2 & 0,0 & 36,4 \\
\hline Demais pa & 57,3 & 73,8 & 0.6 & 0.8 & 0,1 & 4,0 & 0.7 & 0,3 & 12,0 & 3,7 & 200 & 1710 \\
\hline Total & 814,4 & 361,7 & 44,2 & 61,3 & 80,3 & 135,0 & 93,4 & 146,7 & 324,3 & 451,3 & 991,1 & $3.503,7$ \\
\hline
\end{tabular}

Fonte: (GM, 22/10/92) (Dados da Firce/Divap - Banco Central do Brasil).

Obs. Apesar de não se dispor de dados, pelos balanços dos bancos, pode-se afirmar que a maioria dos investimentos brasileiros no exterior säo investimentos no sistema financeiro (equivalente ao valor das dependências no exterior no ativo permanente dos balanços)

Além disso, a maioria dos bancos que constam na Tab. 10 possuem agências ou escritórios de representação em Nova York ou Londres. O Bamerindus, p. ex., é o primeiro no financiamento de importações, sendo grande parte dos recursos obtida com a agência de Nova York, a qual tinha ao final de 1992 um quadro de 600 funcionários qualificados e ativos de US $\$ 790$ milhões. O Itaú, além de possuir uma

\footnotetext{
${ }^{12}$ As subsidiárias são Banco Real International Incorporated, Banque Real de Côte d' Ivoire, Banco Real del Paraguay, Real Paraguay de Seguros e Banco Real de Colômbia.

${ }^{13}$ A expansăo dos bancos brasileiros para os "paraísos fiscais", nesse periodo, seguiu a tendência global do sistema financeiro internacional, como ilustra o caso dos bancos japoneses (Ferreira e Freitas, 1990)
} 
agência em Grand Cayman, ${ }^{14}$ detém uma subsidiária integral também neste local, o que permite aumentar as operações externas sem o risco cambial. $O$ Unibanco conta também com dependências externas e se associou depois de $1989 \mathrm{com}$ alguns bancos estrangeiros, propiciando maior participação no lançamento de export notes, eurobônus, ações, em operaçōes de hedge em fundos de renda fixa e no mercado flutuante de divisas. Já o Bradesco detém expressiva parcela do mercado de câmbio e se destaca no financiamento das exportações através de Adiantamentos de Contrato de Câmbio (ACC).

O Nacional tem notável participação externa na captação de commercial papers, eurobônus, além de oferecer conta corrente, CDBs, e o atendimento de private banking nas agências externas. Esse banco possui uma rede de bancos conveniados e um banco no Paraguai (o Interbanco, com 4 agências), que permite maior alavancagem de recursos e de receitas externas. $O$ Banespa também possui o Banco Del Paraguay no Paraguai, com sete agências, além de ter ampliado a participação no Mercosul através de convênios com bancos nessa área, evitando assim, os custos das remessas de divisas para a instalação de agências no exterior.

Por fim, voltou-se a cogitar em 1991/1992 da instalação de um centro financeiro no Rio Janeiro (o Rio-Dólar) Caso se efetive essa decisão, as vantagens seriam a geração de demanda por serviços e o aumento do emprego de mão-de-obra especializada no País, além da baixa tributação nas transações financeiras. As desvantagens seriam a maior atração para os bancos estrangeiros se instalarem no País, ou se expandir no caso dos já instalados, o que aumentaria a internacionalização do sistema financeiro, além dos riscos de se perder em funding estimado em US $\$ 60$ bilhões de dólares, essencial ao financiamento produtivo e que seria o montante que o País tem depositado no exterior (ver, Yoshino, 1992). Em sintese, as principais restrições que os bancos brasileiros enfrentam no exterior, que impedem uma projeção maior no cenário internacional, são a acirrada concorrência externa, a dívida externa e a alta inflação interna, que aumenta o risco cambial.

\section{CONSIDERAÇÕES FINAIS}

Este artigo evidenciou inicialmente que a reforma bancário-institucional da década de 60 foi fundamental para a internacionalização do sistema financeiro nacional. Todos indicadores focalizados, ou seja, investimento estrangeiro, captações em depósitos, empréstimos outorgados e captações em obrigações externas, apontaram para uma crescente internacionalização depois de março de 1990. Além do mais, a liberalização propiciada pela criação do banco múltiplo e pela abertura da economia, também tiveram papel destacado para o aumento da participação dos bancos estrangeiros no mercado interno, bem como das operações externas dentro das atividades dos bancos nacionais privados e estatais, ou seja, das captações e aplicações externas

Os bancos estrangeiros também foram atingidos pelo bloqueio monetário, pela recessão e pelas taxas de juros elevadas internas do período 1990/1991 e, por isso,

\footnotetext{
${ }^{14}$ Pode-se dizer que um "paraiso fiscal" propicia a isenção fiscal do Imposto de Renda nas operações bancárias, entre outros benefícios fiscais e financeiros. Além de Grand Cayman, outros "paraísos fiscais" são Luxemburgo, Bahamas, Bermudas e Panamá
} 
adotaram medidas de ajuste como a recuperação de dívidas, o corte de despesas, e a diversificação de operações para o mercado de capitais, comércio exterior, entre outros segmentos. Conclui-se que a atuação dos bancos estrangeiros no País se restringe ao atendimento da parcela da população com um perfil de renda de alto poder aquisitivo formada pelas classes média-alta e alta, isto é, tais instituições raramente atuam com o pequeno poupador ou o micro e o pequeno empresário. $\mathrm{Ou}$ seja, são operações que envolvem grande parcela de recursos e uma pequena minoria da população, representada por grandes empresas e por pessoas de alto padrão de vida. Sendo assim, os bancos estrangeiros atuam indiretamente para a manutenção e o agravamento de perfil concentrado da distribuição interna de renda.

Por outro lado, os grandes conglomerados financeiros privados e estatais se mostraram bastante ativos na captação externa de eurobônus, commercial papers, e linhas de crédito para comércio exterior no periodo 1991/1992. Ademais, as agências dos bancos para comércio exterior, depois inicialmente de passar por um período de ameaça de iliquidez, foram capitalizadas e se constituíram em importante alavanca de recursos externos para o País principalmente depois da regularização parcial dos compromissos da dívida externa e da queda das taxas de juros internacionais, em 1991,

\section{BIBLIOGRAFIA}

BACHA, Edmar L. Entre a acomodação e o confronto os dilemas da renegociação externa brasileira, 1983-1987. Revista de Economia Politica. São Paulo, v.8, n.2 (30), p. 49-66, abr/jun., 1988.

BAER, Mônica. A internacionalização financeira no Brasil Petrópolis: Vozes, 1986.

BALANÇO ANUAL 1991. Ineficientes ficarão de fora. São Paulo, Gazeta Mercantil, v.15, n. 15, p 370-385, 1991.

BALANÇO ANUAL 1992. Depois da tormenta, a bonança. São Paulo, Gazeta Mercantil, v.16, n. 16, p. 384-399, 1992

BALANÇO DOS BANCOS publicados no jornal Gazeta Mercantil (Banco do Brasil, 19/02/93; Banespa, 11/03/93; Bamerindus, 06 e 08/02/93; Nacional, 27/21/93; Unibanco, 03/02/93; Itaú, 11/02/93; Econômico, 16/02/93; Bradesco, 21/01/93; BBA, 28/01/93; Banestado, 02/04/92; Bandeirantes, 17/03/92; BCN 12/03/92; Noroeste, 25/02/92)

BATISTA Jr. , Paulo Nogueira, BELLUZO, Luiz Gonzaga de Mello. Reforma fiscal, âncora cambial e estabilização econômica. Gazeta Mercantil. São Paulo, 12 de junho, p.5.

BOLETIM MENSAL DO BANCO CENTRAL DO BRASIL. Brasilia, v. 26, n. 5, mai., 1990. (Separata)

BOLETIM MENSAL DO BANCO CENTRAL DO BRASIL. Brasilia, v.27, n. 4, abr., 1991. (Separata).

BOLETIM MENSAL. DO BANCO CENTRAL DO BRASIL.. Brasília, v 28, n.s 7, 8 e 9 jul/ago/set, 1992. (Separata).

BOLETIM MENSAL DO BANCO CENTRAL DO BRASIL. Brasília, v.28, n.s 10, 11 e 12, out/nov/dez, 1992a. (Separata).

BURLE, Lauro L.obo A política monetária e as taxas de juros no Plano Collor. Analise Econômica. Porto Alegre, FCE/UFRGS, ano 10, n.18, p.83-94, nov., 1992.

BURLE, Lauro Lobo. A política de comércio exterior e a abertura do mercado de capitais: 1990. 1992". Revista de Administraçăo Pública. Rio Janeiro, FGV, v. 27, n.3, p.98-114, jul/set 1993.

CARNEIRO DOS SANTOS, Gilton Os bancos credores e a divida brasileira. Revista de Economia Politica. São Paulo, v.11, n. 2(42), p.139-151, abr.jun., 1991.

CAVALCANTI, Carlos Brandão. Transferência de recursos ao exterior e substituição de divida externa por divida interna. Tese (Mestrado). Brasilia: Universidade de Brasília, 1987.

DIÁRIO DO COMÉRCIO E DA INDÚSTRIA (DCI). A estratégia do BC: capitalização externa, São Paulo, p.12, 09/10/90.

EXAME. O melhor negócio do mundo - A indústria e o comércio gemem e sangram, mas os bancos continuam a exibir esplêndido lucros. São Paulo, abril, ano 24, n.13, p 56-68, 24/06/92.

FERREIRA, Carlos Kawall, FREITAS, Maria Cristina Penido de. Possibilidades de acesso voluntário do Brasil ao mercado internacional de eurobônus. A inserção internacional do Brasil nos anos 90 . 
São Paulo, CORECON/SP, Seminário, Anais, v 1, p.303-317, mar. 1990.

FIANI, Ronaldo. Desempenho dos bancos comerciais brasileiros, 1981-1986. Estudos económicos. São Paulo, FEA/USP, v. 19, n.1, p.25-62, jan./abr. 1989.

FRANCO, Gustavo H. B. Aspectos do reforma financeira. Conjuntura Económica. Rio de Janeiro, FGV, p. 34-36, dez. 1991.

GAZETA MERCANTIL. Os bancos e os banqueiros terão de mudar Edição especial - Os 70 anos, São Paulo, p.33, 14/09/90

GAZETA MERCANTIL Os negócios que deram bom lucro no ano passado. Relatório - Os bancos Săo Paulo, p. 1 e 4, 31/03/92.

GAZETA MERCANTIL. Citibank se reestrutura para competir. São Paulo, p. 18, 08/10/92.

GAZETA MERCANTIL. Brasil investiu menos no primeiro semestre. São Paulo, p. 5, 22/10/92.

GAZETA MERCANTIL. Inaugurado o Banque Banespa Internacional São Paulo, p 1 e 17, 27/11/92.

IESP/FUNDAP. Reforma do sistema financeiro brasileiro - anteprojeto da lei complementar do sistema do sistema financeiro. O Formato Institucional do sistema monetário e financeiro: um estudo comparado (0-0070). Säo Paulo, Relatório Parcial n.1, Convênio Fundap/ Secretaria da Ciência e Tecnologia e Desenvolvimento Econômico do Estado de São Paulo, 1990

MAIA, César. Sistema financeiro: outra filosofia. Conjuntura Económica. Rio de Janeiro, FGV, p.3133, dez. 1991.

MENDES, Aldo Luiz. O mito da modernidade e a nova lei do sistema financeiro nacional Carta de Conjuntura. Brasília, CORECON/DF, ano 6, n.29, p.21-23, nov/dez-jan/fev 1992.

BANCO CENTRAL DO BRASIL. Minuta da resolução 1.524 sobre o banco múltiplo Brasília, set. 1988

MUNHOZ, Dércio Garcia. Dívida do país é administrável. Folha de Såo Paulo. p.3, 10/06/1989.

OLIVEIRA, Gesner, SUZIGAN, Luis. $O$ acordo da dívida externa: uma avaliação preliminar. Jornal do Economista. São Paulo, CORECON/SP, n.48, p.3, jul. 1992.

PORTELLA FILHO, Petrônio. Dívida externa: lições da renegociação brasileira de 1988. Estudos Económicos. São Paulo, FEA/USP, v. 21, n.2, p. 161-211, mai./ago 1991.

RELATÓRIO ANUAL DO BANCO DO BRASIL. Brasilia, 1991.

REVISTA BANCÁRIA BRASILEIRA. Rio de Janeiro, ano 58, n 686, jul. 1990.

REVISTA BANCÁRIA BRASILEIRA. Rio de Janeiro, ano 59, n.692, jan. 1991.

REVISTA BANCÁRIA BRASILEIRA. Rio de Janeiro, ano 59, n.697, jul. 1991 a.

SERRA, José. A lei do sistema financeiro: uma proposta Conjuntura Económica, Rio de Janeiro, FGV, p. 43-45, dez. 1991

SOUZA, Francisco Eduardo Pires de. As metamorfoses do endividamento externo In: CASTRO, Antônio Barros de, SOUZA, Francisco Eduardo Pires de. A economia brasileira em marcha forçado. $2^{\text {a }}$ ed. Rio de Janeiro: Paz e Terra, p. 97-189, 1985.

SUZIGAN, Wilson. Política comercial e perspectivas da indústria brasileira. Indicadores económicos FEE. Porto Alegre, v.20. n.4, p.121-133, jan. 1993.

YOSHINO, Joe. Tratamento do capital e bancos estrangeiros Informaçðes FIPE. São Paulo, FEA/USP, n. 142, p. 12 - 16, jun./jul. 1992.

\section{ABSTRACT \\ THE INTERNATIONALIZATION OF FINANCIAL SYSTEM: 1990-1992}

This article analyzes the factors involved in the internationalization of the Brazilian financial system, giving emphasis to the institutional changes which occurred during the sixties, the foreign debt the country incurred in during the seventies and eighties, the banking reform of 1988 , and the opening of the economy wich began in March 1990. The text tries to show, on the one hand, the role played by foreigh banks in 1990/1992, as well as the adjustment these banks underwent, and, on the other hand, the activities of Brazilian banks abroad during the same period. The article, concludes that foreign banks contibute to the maintenance of the income-concentration profile of the Brazilian economy and that the activities of Brazilian banks abroad is essential for internal sovereignty. 